Terr. Atmos. Ocean. Sci., Vol. 18, No. 5, 859-878, December 2007

\title{
Lateral Variations of Rayleigh-Wave Dispersions in the Philippine Sea Region
}

\author{
Wen-Yen Chang ${ }^{1}$, Guey-Kuen Yu ${ }^{2,}{ }^{3},{ }^{*}$, Ruey-Der Hwang ${ }^{4}$, and Jiou-Kwei Chiu ${ }^{3,5}$
}

(Manuscript received 29 August 2006, in final form 26 April 2007)

\begin{abstract}
Fresh two-dimensional group and phase-velocity distribution maps of the Philippine Sea and surrounding areas are constructed using the tomographic inversion of more than 2500 Rayleigh-wave dispersion curves in the 20- to 120-sec period range. The results show that, for the periods used, both the group and phase-velocity variation patterns are very close to the geological and topographic features and are also consistent with previous studies of magnetic anomalies and evolutionary history of the Philippine Basin. On average, the periods of the peak group-velocity for the West Philippine Basin and the Oki-Daito ridge are about 40 and 32 sec for the Parece Vela and Shikoku basins. This implies that the lithosphere of the western Philippine Sea Basin is thicker, which is related to plate cooling and seafloor age. For most of the examined periods, the high velocity symmetry of the two sides of the Central Basin Ridge in the West Philippine Basin coincides well with the evolutionary history of the Philippine Sea Basin, and may be taken as additional evidence confirming the existence of the ridge. The group and phase-velocity distributions for periods longer than $\mathbf{8 0}$ sec are smooth throughout the whole Philippine Sea Basin, which implies that the upper mantle beneath the Philippine Sea Basin is nearly homogeneous at depths of $100-200 \mathrm{~km}$. Moreover, the group and phase velocities in the region of
\end{abstract}

\footnotetext{
1 Department of Natural Sciences and Mathematics, National Science Council, Taipei, Taiwan, ROC

2 Department of Civil Engineering, Vanung University, Chung-Li, Taiwan, ROC

3 Institute of Geophysics, National Central University, Chung-Li, Taiwan, ROC

4 Department of Geology, Chinese Culture University, Taipei, Taiwan, ROC

${ }^{5}$ General Education Center, Chin Min Institute of Technology College, Miaoli, Taiwan, ROC

* Corresponding author address: Prof. Guey-Kuen Yu, Department of Civil Engineering, Vanung University, Chung-Li, Taiwan, ROC; E-mail: yugk@msa.vnu.edu.tw doi: 10.3319/TAO.2007.18.5.859(T)
} 


\begin{abstract}
the East Volcano Belt and Active Marginal Basin remain almost constant in the 36- to 80-sec period range, which indicates that the boundary between the lithosphere and asthenosphere is probably not obvious in this area.
\end{abstract}

\title{
(Key words: Group-velocity, Phase-velocity, Tomographic inversion, Philippine Sea Basin)
}

\section{INTRODUCTION}

The Philippine Sea Basin is a small tectonic plate lying between the Pacific and Eurasian Plates. Tectonically, the Philippine Sea Plate consists of several basins, ridges, and trenches (see Fig. 1). To the east, the Pacific Plate subducts at a high angle westward into the Philippine Sea Plate to form the Izu-Bonin, Mariana, Yap, and Palau trenches, whereas to the west and north, the Philippine Sea Plate subducts north-westward under the Eurasian Plate to form the Ryukyu-Taiwan-Philippine arc chain. Using palaeomagnetic and drilling data, Seno and Maruyama (1984), Seno (1988), and Hall et al. (1995) described the possible tectonic evolutionary process. After analyzing the available geophysical data, Sdrolias et al. (2004) also created a detailed plate model of the Parece Vela and Shikoku basins. Figure 1 shows geological and topographic features in the Philippine Sea Basin. Basically, the Philippine Sea Basin is divided into three basins (i.e., the Shikoku, Parece Vela, and West Philippine basins) by the Kyushu-Palau Ridge. Remarkably, there is an inactive ridge located at the center of the West Philippine basin related to the generation of this basin. Previous studies show that these basins have various seafloor ages: the West Philippine basin is about 40 - 50 Ma, the Shikoku-Parece Vela basin is about $12-30 \mathrm{Ma}$ and the Mariana Trough is about $0-6 \mathrm{Ma}$ (cf. Hussong and Uyeda 1981; Seno 1988; Okino et al. 1994, 1998). In addition, the West Philippine basin has low heat flow, whereas the tectonically active regions, such as the Mariana arc, Philippine trench and Ryukyu arc, are characterized by a pattern of high heat flow (Watanabe et al. 1970). From the investigations of bathymetric magnetic profiles and submarine topography, BenAvraham et al. (1972) suggested the existence of an extinct spreading center in the West Philippine Basin. This region is worth studying because of its structural variety, lateral variations in thickness and the velocity distributions of the Philippine Sea Basin.

Surface wave data analysis has been recognized as one good approach to the study of the crustal and upper mantle structures of the Earth, especially in relation to lateral velocity variations. Past studies of surface waves across the Philippine Sea and the surrounding areas have provided some important information about lateral variations in plate thickness and upper mantle shear velocities (e.g., Seekins and Teng 1977; Yu and Chang 1991; Oda and Senna 1994; Lebedev et al. 1997; Nakamura and Shibutani 1998). Although there are some differences between the results, especially for plate thickness in relation to geological and topographic features, the fact that there is lateral variation in structure beneath the Philippine Sea is revealed. Oda and Senna (1994) used tens of Rayleigh- and Love-wave group velocities to derive the regional features of the Philippine Sea region, which are regionalized according to 
the sea-floor topography and evolutionary age. Their results suggest that the plate thickness in the West Philippine Basin (including the Ridges) is about $60 \mathrm{~km}$ while it is about $40 \mathrm{~km}$ in the Shikoku, Parece Vela and Active Marginal basins. Since 1995, tomographic inversion with huge high-quality dispersion curves has been extensively used to establish global-scale surface wave group- and phase-velocity maps (e.g., Ekström et al. 1997; Larson and Ekström 2001). Regional-scale tomographic images of surface waves, such as in the Philippine Sea or China, have been also made to investigate their tectonics implications (e.g., Lebedev et al. 1997; Nakamura and Shibutani 1998; Hwang 1999). The 3-D shear velocity structure of the upper mantle to depths of 200 - $300 \mathrm{~km}$ beneath the Philippine Sea has been derived by Levedev et al. (1997) from the waveform inversion of about 300 Rayleigh waves. Later, Nakamura and

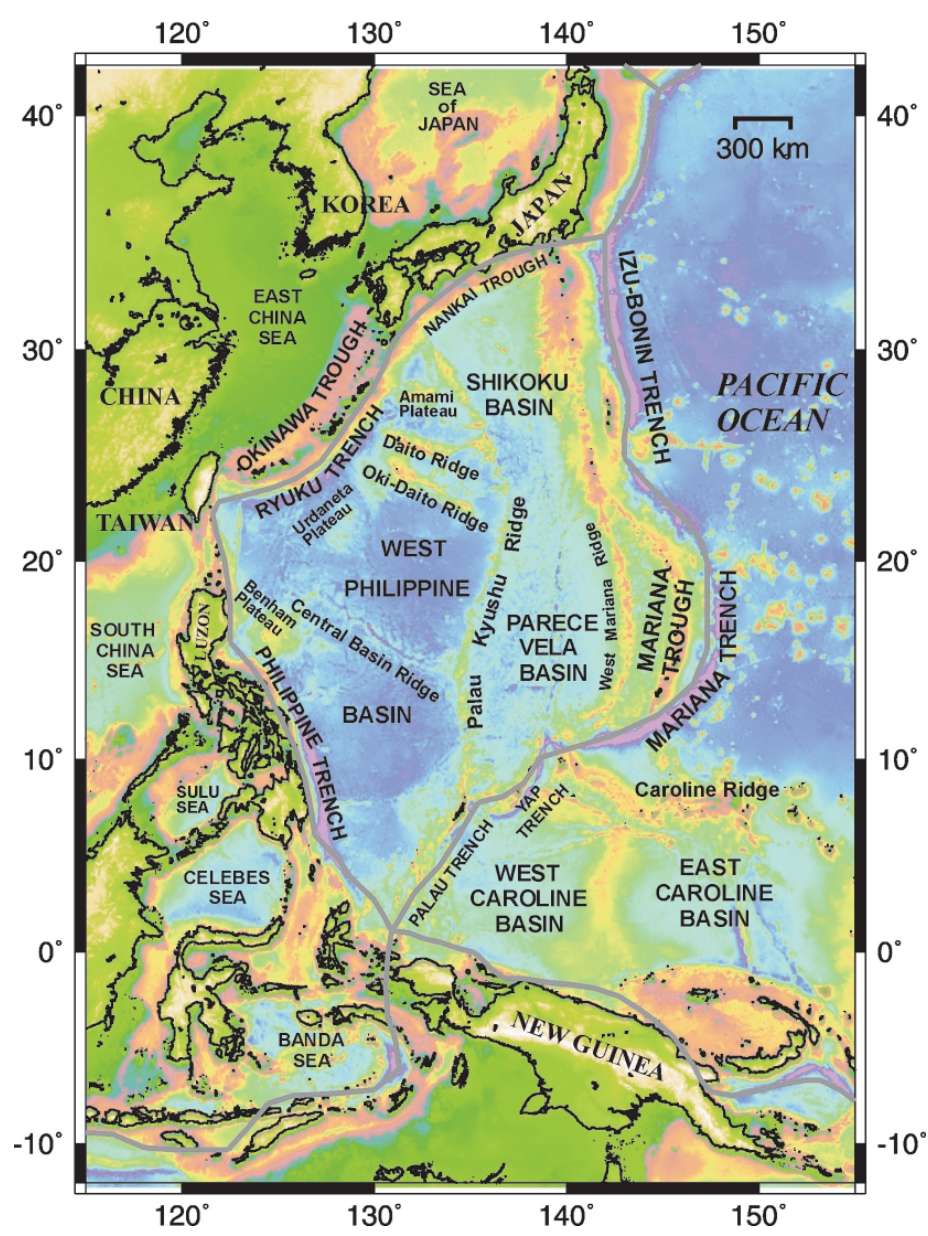

Fig. 1. Topographic map of the Philippine Sea Basin and its surroundings. The thick gray lines denote the plate boundaries. 
Shibutani (1998) modified this structural model by the inversion of more than 900 Rayleighwave phase-velocities. The results of both studies indicate that there are low S-wave velocities in the West Philippine Basin that are related to the extinct Central Basin Ridge (e.g., Lebedev et al. 1997; Nakamura and Shibutani 1998). Rayleigh-wave phase velocities obtained from the broadband OBS array in the Philippine Sea region also give systematically lower values than those obtained in the Pacific for comparable geological ages (Isse et al. 2004). In addition, crustal thickness inferred from seismic refraction profiles reveals that the crust of the Philippine Sea Basin is $12 \mathrm{~km}$ thick and that the crust of the Oki-Daito ridge is thicker (Murauchi et al. 1968).

In recent years, surface-wave tomography with finite-frequency theory has been actively addressed. A few studies stressed that tomographic results using the finite-frequency theory are superior to those using the traditional ray theory (a great-circle path assumption under high-frequency approximation) (e.g., Zhou et al. 2005). However, other studies (Sieminski et al. 2004; Levshin et al. 2005; Trampert and Spetzler 2006) found that results using the ray theory are similar to those of the finite-frequency theory when utilizing reasonable ray coverage in the study region. Sieminski et al. (2004) further pointed out that finite-frequency effects can be counterbalanced by a physically-based regularization of the tomographic inversion or dense ray coverage in the study region (e.g., Levshin et al. 2005). Trampert and Spetzler (2006) also stated that tomographic models from finite-frequency theory and ray theory are statistically similar. Experiments of Sieminski et al. (2004) stressed that regional surface-wave tomography can be safely conducted using the great-circle ray theory assumption when good path coverage and short path length are used. Additionally, regarding elastic anisotropy effect on surfacewave tomography, Suetsugu and Nakanishi (1987) stressed that the trade-off between lateral velocity variation and azimuthal variation is weak. In general, azimuthal anisotropy of Rayleigh waves is less than $2 \%$ for periods less than $200 \mathrm{sec}$.

In this study, the tomographic inversion technique with traditional ray theory (Hwang 1999 ) is used to construct fresh 2-D group- and phase-velocity maps of the Philippine Sea region using more than 2500 group- and phase-velocity dispersion Rayleigh wave data in the 20 - to 120 -sec period range. Due to the usage of dense ray coverage and short ray-path length, we do not take the finite-frequency effect and azimuth anisotropy effect into account in the tomographic inversion. A comparison of the velocity variation patterns for these periods from this study with the geology/topography of the study area should be able to interpret the evolutionary history of the Philippine Sea Basin.

\section{DATA}

The fundamental-mode Rayleigh-wave group- and phase-velocity dispersion curves are determined from long-period vertical-component seismograms recorded at stations in two different networks, including 7 GSN stations (Global Seismographic Network), i.e., TATO, SSE, INCN, MAJO, GUMO, DAV and PMG, and 11 OHP stations (Ocean Hemisphere network Project), i.e., BAG, INU, ISG, JAY, MCSJ, OGS, PALU, PHN, TGY, TJN, and TSK. Figure 2 shows the locations of the 18 stations and the 950 earthquakes that occurred from 1980 to 2002. Seismograms are provided by IRIS (Incorporated Research Institutions for Seismology) from 
1980 to 2002 and OHP DMC (OHP Data Management Center) from 1995 to 2001. Earthquakes located within and around the Philippine Sea region (latitude: $-10 \sim 40^{\circ} \mathrm{N}$, longitude: $116 \sim 154^{\circ} \mathrm{E}$ ) with a magnitude (Ms) equal to or greater than 5.5 are selected from the Harvard CMT (Centriod Moment Tensors) catalog. In order to get good surface-wave energy excitation, the focal depths are constrained to be less than $100 \mathrm{~km}$. They are used to prepare Rayleigh wave group- and phase-velocity maps. Before the group and phase velocities can be determined, the instrumental response has to be removed from the original velocity seismogram, and then the corrected velocity seismogram is transferred to the displacement one. These recordings are also filtered in the frequency range of $0.1-0.0067 \mathrm{~Hz}$ to protrude the fundamental-mode Rayleigh waves. A detailed analysis of the dispersion curve is discussed in the next section. More than 2500 Rayleigh-wave dispersion curves with periods between 20 and 120 seconds are used to map the 2-D Rayleigh-wave group and phase velocities of the Philippine Sea region .

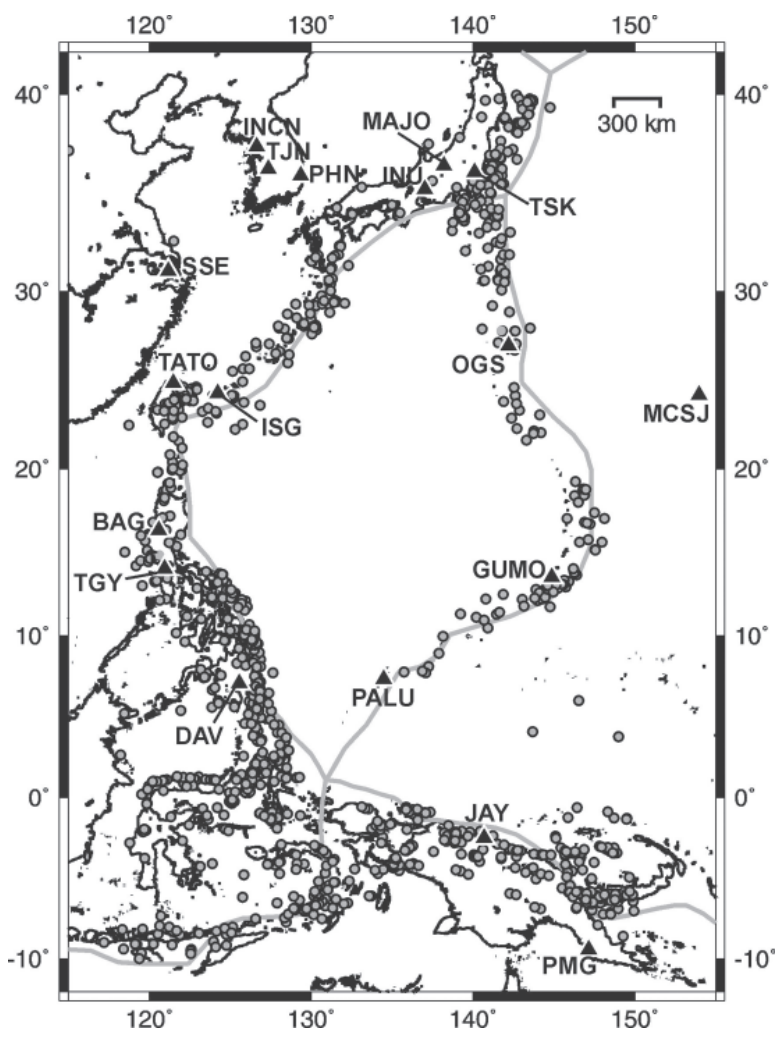

Fig. 2. Map showing the locations of seismographic stations and earthquakes used in this study. The triangles denote the IRIS and OPH stations. The circles indicate events with a magnitude of 5.5 and greater. The thick gray lines denote the plate boundaries. 


\section{GROUP AND PHASE VELOCITY DETERMINATION}

The estimate of surface-wave velocity dispersion is to determine the arrival time of a signal at a particular period. Such a procedure is generally referred to as the frequency-time analysis technique (FTAN) (cf. Herrmann 1973). In order to conveniently obtain dispersion curves, fundamental-mode Rayleigh waves are extracted from the vertical-component seismograms through a time window with group velocities of $2.0-5.0 \mathrm{~km} \mathrm{~s}^{-1}$ to avert the interference of body waves, especially S-waves.

We adopt Multiple Filter Technique (MFT) (Dziewonski et al. 1969) to determine the surface-wave group-velocity. A Gaussian filter is used to settle the complement between the time and frequency-domain of the signals (Herrmann 1973). Each signal is filtered through the Gaussian filter at a given central period (or frequency). The maximum amplitude of the filtered signal is treated as the main energy group arriving at the receiver. The group velocity can then be easily estimated by $U(T)=L / t_{\max }(T)$, where $L$ is the epicentral distance from source to station, $U(T)$ and $t_{\max }(T)$ are the group-velocity and the corresponding group-delay time of the maximum amplitude of the filtered signal at period $T$. Figure 3 illustrates the group-velocity estimation for two seismograms using this technique. In Fig. 3, solid circles denote the estimated group velocities at periods of $16-120 \mathrm{sec}$, and the contour lines stand for the Rayleigh-wave energy plotted in an interval of $5 \mathrm{db}$.

To calculate the phase-velocity related only to the velocity structures, one should extract the phases from the observed Rayleigh waves. For this reason, a few phases unrelated to the velocity structure, such as from the source and the instrumental response, should be excluded from the phase-velocity calculation of the surface-wave. The initial phase of the source can be theoretically calculated from a known focal mechanism and the velocity structure at the source area (cf. Wang 1981). In this study, the single-station method is employed to determine the phase velocity of the surface wave (e.g., Yu and Mitchell 1979). The formula for phase-velocity determination can be written in the following form:

$$
C_{R}(T)=\frac{L}{\left(\phi_{S R}-\phi_{0 R} \pm N\right) T},
$$

where $C_{R}(T)$ denotes the Rayleigh wave phase velocity at period $T, \phi_{S R}$ is the station phase after removing the instrumental response in fractions of a circle, and $\phi_{0 R}$ is the initial phase of the source in fractions of a circle. $L$ represents the epicentral distance linking the source and the station and $N$ is an arbitrary integer. In general, for a globally average velocity model, the value of the phase-velocity at a period of $100 \mathrm{sec}$ is about $4.0 \mathrm{~km} \mathrm{sec}^{-1}$. Based on the above, we modulate the $N$-value to detect the rationality of the phase velocity determined at long periods. However, a notable problem for eq. (1) is the station phase, which is expressed in discrete form and varies between $-\pi$ and $\pi$ in the frequency-domain. In fact, the station phase should vary continuously with increasing frequency. Therefore, we must unwrap the station phases to form continuous ones. Figure 4 shows two examples depicting the phase-velocity measurements. By detailed analyses of dispersion curves, we obtain more than 2500 Rayleigh waves group- 

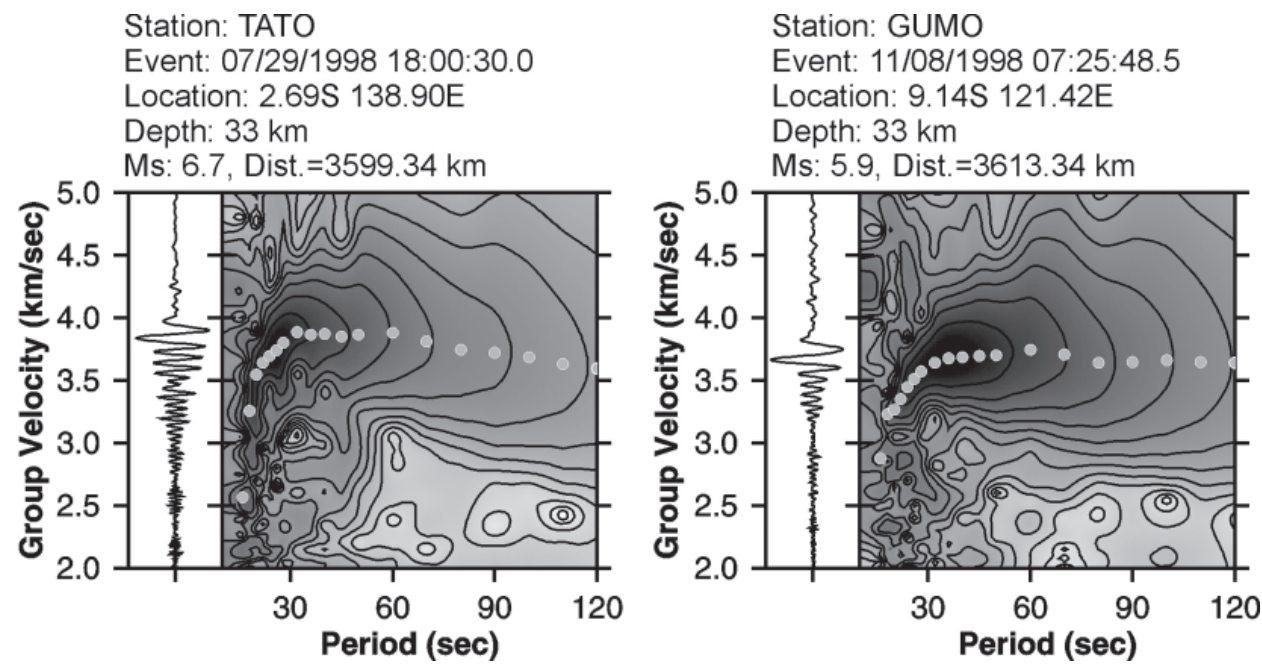

Fig. 3. Examples of group velocities determined by the Multiple Filter Technique. The contours are plotted at an interval of $5 \mathrm{db}$. The solid circles are the group velocities determined for given periods. The seismograms are also shown in amplitude vs. group-velocity.


Fig. 4. Examples of phase-velocity determined by using the single-station method. The station phase and initial phase of the source are also shown in the upper panels. The lower panels indicate the phase velocities determined for given periods. 
and phase-velocities with periods of $20-120 \mathrm{sec}$ and ray-path length less than $5000 \mathrm{~km}$. Figure 5 shows the distribution of Rayleigh waves across the Philippine Sea Basin and the surrounding areas.

\section{TOMOGRAPHIC METHOD}

Owing to the dense ray coverage, ray-path length less than $5000 \mathrm{~km}$, and used period, $\sim 120 \mathrm{sec}$, in our regional study, the tomographic problem using ray theory with a smoothing regularization are reasonable under not considering finite-frequency effect (cf. Sieminski et al. 2004; Levshin et al. 2005; Trampert and Spetzler 2006). Also, the relationship between lateral velocity variation and azimuthal variation is weak (cf. Suetsugu and Nakanishi 1987), so the anisotropy effect is not included in the tomographic inversion. We adopt the pure-path method (cf. Knopoff 1969), known to be a high-frequency approximation, to examine the lateral varia-



Fig. 5. (Right) More than 2500 Rayleigh-waves traveling through the Philippine Sea region are used in this study. The triangles indicate the stations used as depicted in Fig. 2. (Left) The Philippine Sea region is divided into 399 sub-regions, each of which has a size of $2^{\circ} \times 2^{\circ}$ in latitude and longitude. The numerals within the blocks indicate the block number. 
tions in velocity structure. This method assumes that surface waves travel along a great-circle path from source to station. Wave refraction, i.e., the seismic wave traveling across a boundary of two different geological provinces (or regions), is not taken into account. To investigate lateral velocity variations, model parameterization without a priori regionalization is considered in the tomographic inversion problem. That is, the studied region is divided into a number of sub-regions; each of the sub-regions is then regarded as a homogeneous structure. For a given ray-path across $n$ sub-regions, the travel time, equal to the sum of group/phase delay time of each sub-region, can be expressed as follows:

$$
t_{i}(T)=\frac{L_{i}}{V_{0 i}(T)}=\sum_{j=1}^{n} \frac{L_{i j}}{V_{j}(T)}
$$

where $t_{i}(T)$ is the travel time (group- or phase-delay time) at a particular period $(T)$ for the $i$ th path, $L_{i}$ the epicentral distance in the $i$ th path, and $L_{i j}$ the partial length of the $i$ th path across the $j$ th block. $V_{0 i}(T)$ is the observed group or phase velocity for the $i$ th path, and $V_{j}(T)$ is the groupor phase-velocity of the $j$ th block to be solved.

We transform eq. (2) into matrix form for all used data; eq. (2) can now be rewritten as:

$$
A x=b
$$

The above equation is in standard linear inversion form. Matrix $A$ is commonly called a kernel matrix, which is composed of the ray-path length; i.e., the distance across each of the subregions $\left[L_{i j}\right.$ in eq. (2)]. Vector $x$ indicates an unknown parameter corresponding to slowness $\left[\frac{1}{V_{j}(T)}\right.$ in eq. (2)]. Vector $b$ indicates the observed travel time (group- or phase-delay time). We solve eq. (3) by using a damped least-squares method with a smoothing constraint, which governs the relationship between the sub-regions, to find vector $x$ (e.g., Menke 1989). The solution is obtained by simultaneously minimizing the data misfit $(E)$ and the length of the roughness matrix $(L)$.

$$
E+\lambda^{2} L=|A x-b|^{2}+\lambda^{2}\left(x^{T} D^{T} D x\right)
$$

where $E=|A x-b|^{2}$, that is the a posteriori information, is used to check whether the observed data agree well with the predicted data subsequent to the achievement of inversion; $L=x^{T} D^{T} D x$ indicates the a priori information for regularizing the relationship between the blocks (e.g., Menke 1989). $\lambda^{2}$ is the damping parameter ranging from 0 to infinity for manipulating the relative significances between $E$ and $L$ during tomographic inversion. $D$ is the roughness matrix indicating the relation of a designated sub-region in connection with its nearby sub-regions. In this study, a five-point finite difference approximation of the Laplacian operator is recommended for constructing the smoothing correlation between the sub-regions (cf. Menke 1989; Nakamura and Shibutani 1998; Hwang 1999). After minimizing eq. (4), the 
estimated parameters, $x^{e s t}$, and resolution matrix, $R$, can be expressed as follows:

$$
\begin{aligned}
& x^{e s t}=\left(A^{T} A+\lambda^{2} D^{T} D\right)^{-1} A^{T} b, \\
& R=\left(A^{T} A+\lambda^{2} D^{T} D\right)^{-1} A^{T} A .
\end{aligned}
$$

In the inversion problem, $\lambda^{2}$ is an important parameter that controls the trade-off between the data misfit and the length of the solution roughness (i.e., $|D x|$ ). In eq. (5), the inverse matrix, , $\left(A^{T} A+\lambda^{2} D^{T} D\right)^{-1}$ is derived by the Single Value Decomposition (SVD) technique from the matrix, $\left(A^{T} A+\lambda^{2} D^{T} D\right)$. The SVD algorithm is from the book by Press et al. (1992).

In this study, we divided the Philippine Sea Basin and the surrounding areas into 399 subregions. Each sub-region has a size of $2^{\circ} \times 2^{\circ}$ in latitude and longitude (Fig. 5). Included also is the block number within each sub-region in Fig. 5.

\section{RESULTS AND DISCUSSION}

The damping value is a very important factor in deciding the final model in tomographic problems. We take the 40-s group-velocity as an example to further examine the effect of the damping value on the final tomography. Figure 6 shows three 2-D 40-s group-velocity maps obtained from tomographic inversion by using under-damping, optimal-damping and overdamping values. It is obvious that if the under-damping value is used, the group-velocity map
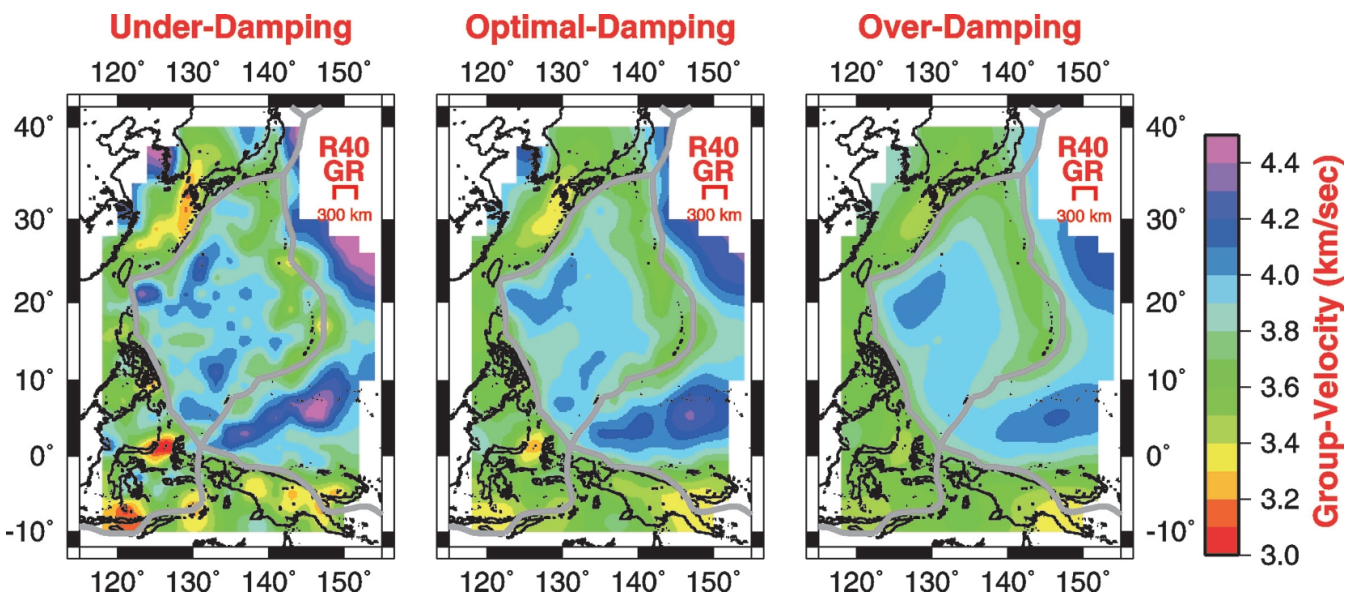

Fig. 6. Three tomographic inversion results obtained by using different damping values for the 40 -sec period group-velocity. The optimal value is objectively determined by the approximate cross-validation technique. 
varies violently and the singularities of velocity show up throughout the Philippine Sea region and its surroundings. On the other hand, the group-velocity map from over-damping tomographic inversion results in over-smoothed velocity variation. Of the three, the velocity distribution on the 2-D group-velocity map, derived from optimal-damping tomographic inversion, is most reasonable. To find the optimal-damping value, we apply the approximate cross-validation technique, which has been described in detail by van Heijst and Woodhouse (1999). For practical work, we first divide the dataset into 10 data subsets, and then solve the tomographic inversion from each arbitrary combination of 9 data subsets by a series of damping values. The curve of the approximate cross-validation (RMS vs. damping value) for each data subset is indicated by the thin lines in Fig. 7a. In order to determine the optimal damping value, we average the approximate cross-validations for the 10 data subsets to find the minimum RMS indicating the optimal damping value. The thick line in Fig. 7a shows the average approximate cross-validation. Using the optimal damping value, the estimated resolutions $(\geqq 0.4$, Fig. 7b) and the resolving kernels of a few given blocks (Fig. 7c) indicate that the lateral

(a)

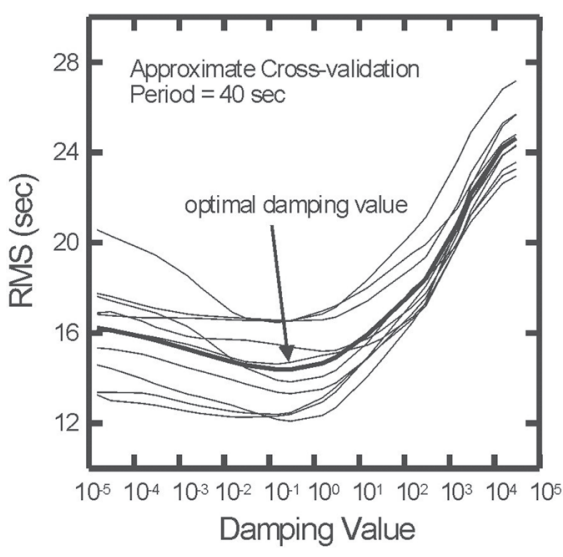

(b)

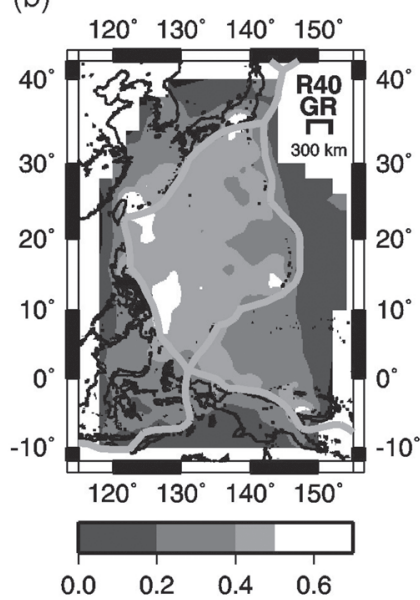

Fig. 7. (a) Optimal damping values determined via approximate cross-validation for the 40-sec period group-velocity. The thin lines denote the approximate cross-validation of the 10 data subsets. The thick line indicates the average of the approximate cross-validation of the 10 data subsets. The minimum value of the RMS indicates the optimal damping value, which is adopted to obtain the final group-velocity maps plotted in the middle of Fig. 6. (b) Resolutions estimated from the optimal damping value for the 40-sec period group-velocity show good resolution of the Philippine Sea region $(\geqq 0.4)$. (c) The resolving kernels are also presented for a few given blocks. The stars denote the target blocks. Each target block has a relatively larger amplitude than the rest of the blocks. 
(c)
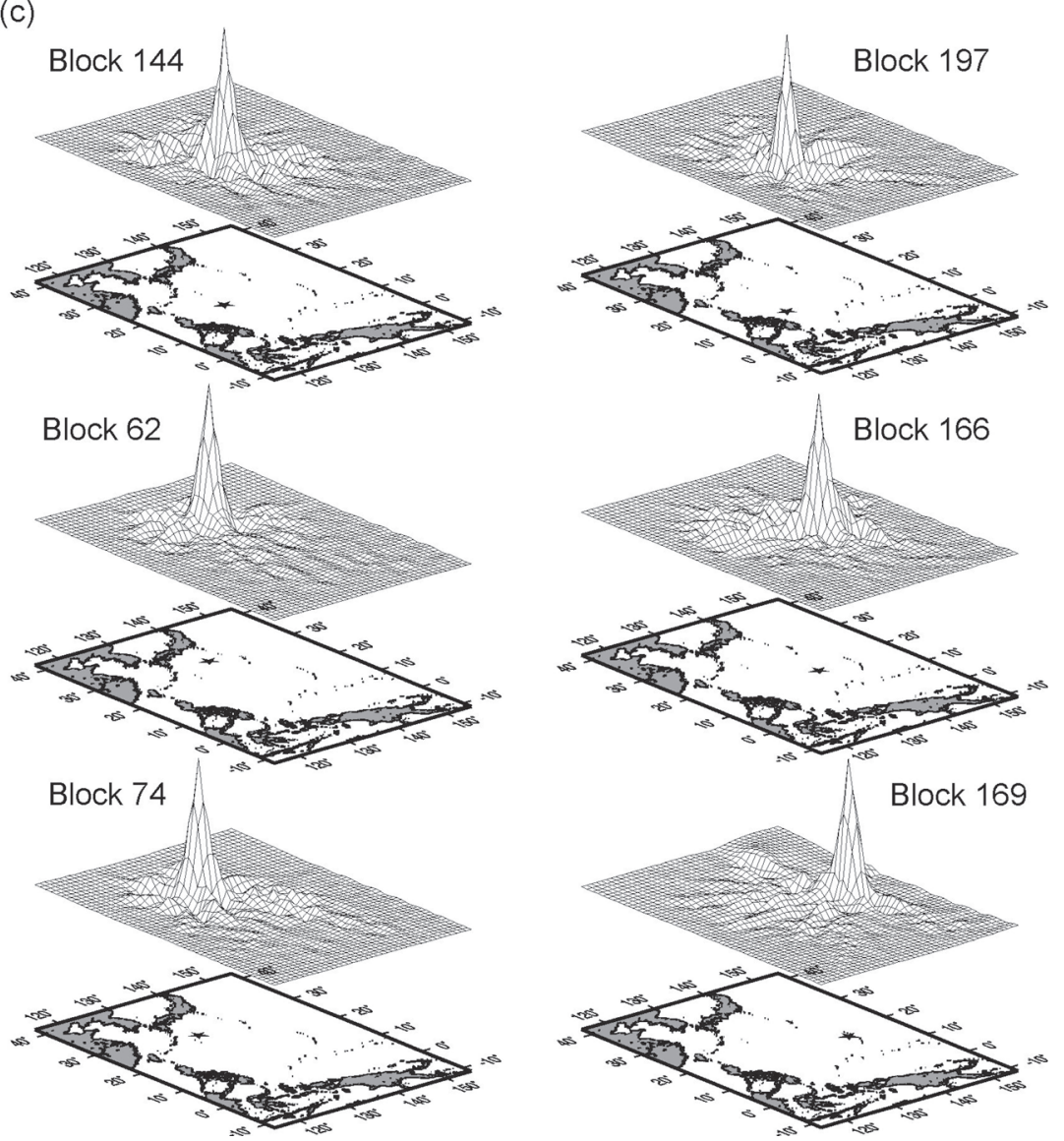

Fig. 7. (Continued)

variation of the group-velocity at the 40-s period can be resolved well not only in the Philippine Sea region but also for the surrounding areas. The group- and phase-velocity maps for the rest of the periods are also derived by utilizing the above-mentioned process (Fig. 7).

For connecting the relationship between the maps of velocity dispersions and depth, the sensitivity kernels for several periods are calculated from an average velocity model of the Philippine Sea region (Tsai 1993) (Fig. 8). The depth of maximum amplitude of the sensitivity kernel for group-velocity seems to appear in the corresponding period; for instance, the maximum amplitude is located at about a $20-\mathrm{km}$ depth for the 20 -s sensitivity kernel and at about a $120-\mathrm{km}$ depth for the 120 -s one. However, depth sensitivity kernels for phase-velocity reflect a deeper depth relative to those for group-velocity. Due to the use of the 120-s phase-velocity, our group- and phase-velocity maps can reflect the uppermost structures of the earth to a depth 
$\delta U / \delta \beta$

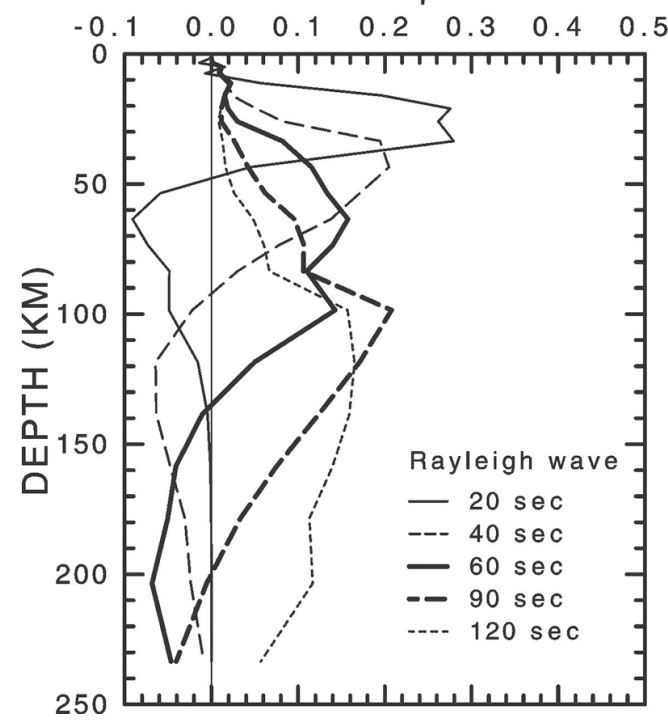

$\delta \mathrm{C} / \delta \beta$

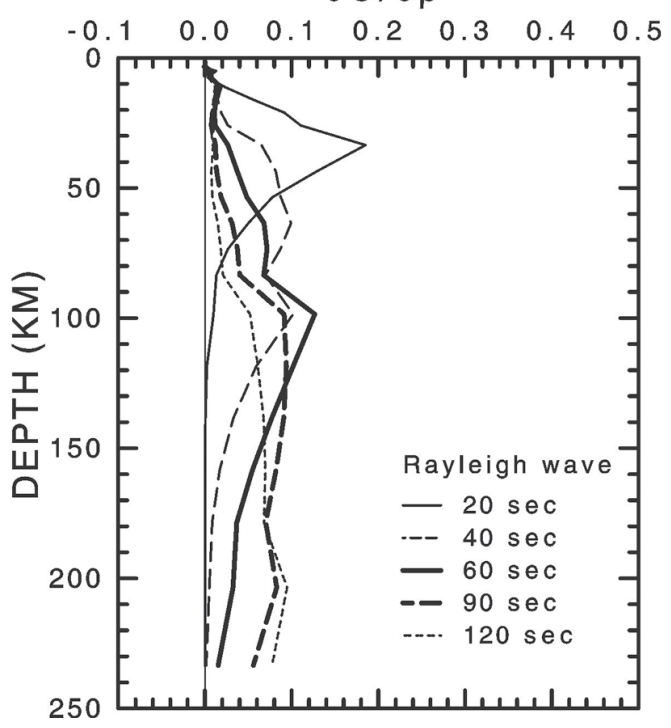

Fig. 8. Depth sensitivity kernels calculated from an average velocity model in the Philippine Sea region (Tsai 1993) for periods 20, 40, 60, 90, and $120 \mathrm{sec}$. The left panel is the partial derivative of group-velocity vs. $S$-wave velocity $(\delta U / \delta \beta)$. The right panel denotes the partial derivative of phasevelocity vs. S-wave velocity $(\delta C / \delta \beta)$.

of $200 \mathrm{~km}$. Figures 9 and 10 show the 2-D group- and phase-velocity maps, respectively, for periods from 20 to $120 \mathrm{sec}$. It can be seen in these figures that the lateral variation patterns in the group-velocity maps are quite similar to those in the phase-velocity maps for corresponding periods. In general, the group-velocity seems more sensitive than the phase-velocity to variation in velocity structure under the Earth (e.g., Yu and Mitchell 1979; Hwang 1999). For this reason, we mainly depend on the group-velocity maps to interpret the lateral velocity variation of the Philippine Sea Basin. The phase-velocity maps are utilized for auxiliary interpretation. On the whole, the group and phase velocities in the western region of the Philippine Sea plate are higher than those in the eastern area. The tectonically active regions, such as the Ryukyu arc, Philippine trench, Mariana arc, etc., have relatively low group and phase velocities (Oda and Senna 1994; Nakamura and Shibutani 1998). In the eastern Philippine Sea, the velocities are faster in the Parece Vela basin than in the Shikoku basin. Similarly, in the western Philippine Sea, the velocities in the Oki-Daito ridge are lower than in the West Philippine Basin. Furthermore, the velocities in the Philippine Sea Basin are also systemically lower than those of the Pacific Ocean for corresponding seafloor ages (Yu and Mitchell 1979; Isse et al. 2004). We also observe variation in the period of the peak group-velocity, which is a good indicator of the 




Fig. 9. 2-D group-velocity maps for periods of $20-120 \mathrm{sec}$. The thick gray lines denote the plate boundaries. The red lines indicate the topographic regionalization (also see Fig. 1). The dashed red line indicates the Central Basin Ridge located in the West Philippine Basin. 'GR' denotes groupvelocity. For 'R20' - 'R120', 'R' denotes Rayleigh-wave, and the number is the period used. 


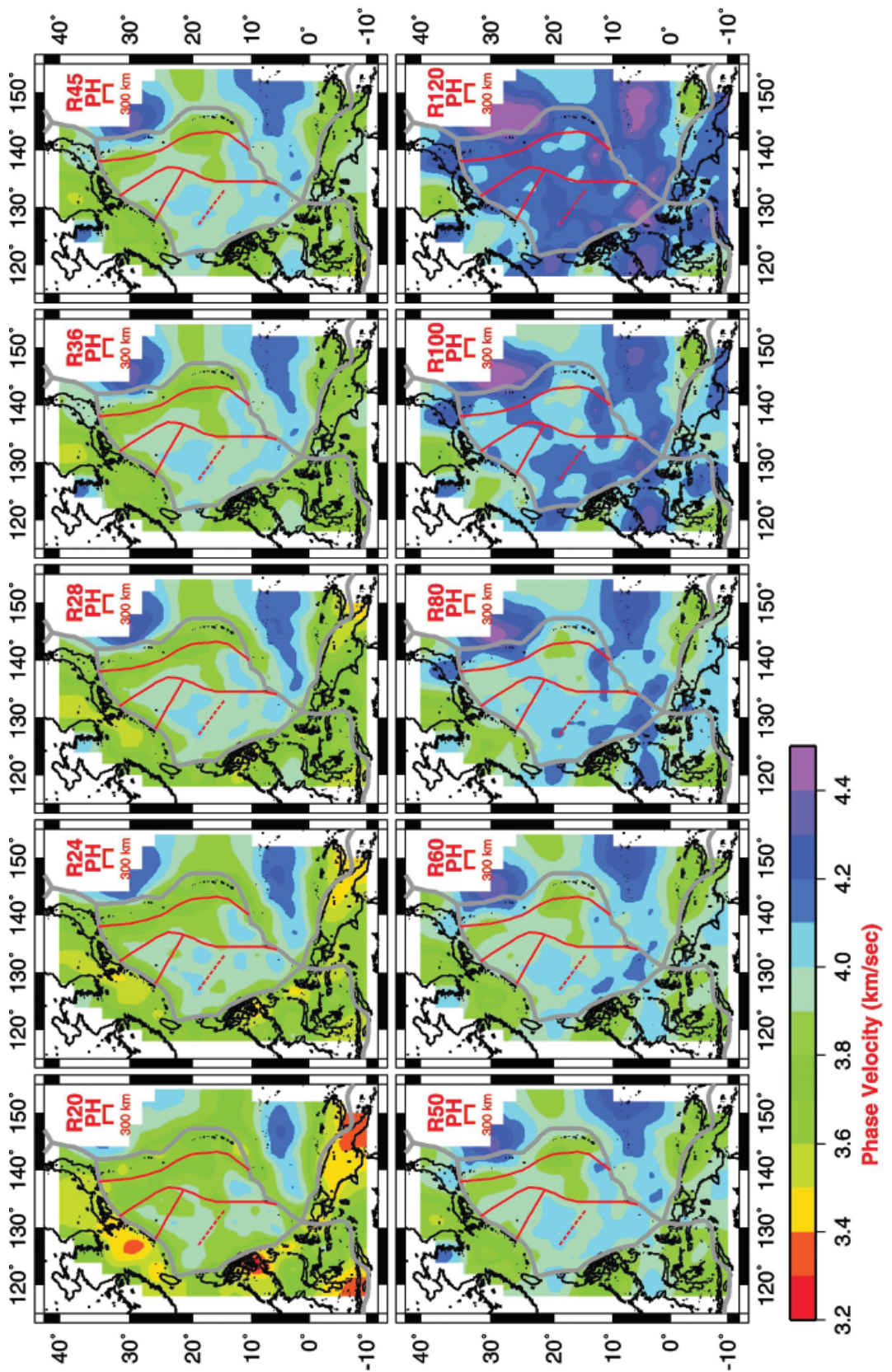

Fig. 10. 2-D phase-velocity maps for periods of $20-120 \mathrm{sec}$. The thick gray lines denote the plate boundaries. The red lines indicate the topographic regionalization (also see Fig. 1). The dashed red line indicates the Central Basin Ridge. 'GR' denotes group-velocity. For 'R20' - 'R120', 'R' denotes Rayleigh-wave, and the number is the period used. 
variation in lithospheric thickness (cf. Yu and Mitchell 1979). On average, the periods of the peak group-velocity are about $40 \mathrm{sec}$ for the West Philippine Basin and the Oki-Daito ridge and $32 \mathrm{sec}$ for the Parece Vela and Shikoku basins, and are roughly connected with seafloor age. The older regions have larger periods than the younger ones. This also implies that the lithosphere of the western part of the Philippine Sea Basin is thicker than that of the eastern part of the region. Oda and Senna (1994) estimated the lithospheric thickness of the Philippine Sea Basin to be $55 \mathrm{~km}$ in the western region and $40 \mathrm{~km}$ in the eastern part. The periods of the peak group-velocity observed in tectonically active regions are not obvious, and the groupand phase-velocities in these regions are mostly lower than the rest of the regions. Perhaps the lithosphere is thin and shear velocity is low in the uppermost mantle in these tectonically active regions (Seekins and Teng 1977; Yu and Chang 1991; Oda and Senna 1994), which are also characterized by high heat flow (Watanabe et al. 1970). Indeed, a further velocity structure inversion is necessary for inferring the lithospheric thickness and uppermost-mantle shear velocity beneath these tectonically active regions.

For group-velocity with periods of less than $50 \mathrm{sec}$, the Philippine Sea is surrounded by low group-velocity anomalies, which might be due to the low velocity of the these arcs in the uppermost-mantle; when the periods of the phase-velocity are larger than $80 \mathrm{sec}$, the Philippine Sea seems to be encircled by relatively high phase-velocity, perhaps due to subduction of the high velocity lithosphere. This can be interpreted as a variation in depth between the Philippine Sea Plate and its surrounding plates (Lebedev et al. 1997). Additional high velocity features are located to the east and southeast of the studied region, i.e., the westernmost Pacific Ocean and the Caroline basin all reveal a high velocity related to plate cooling where the seafloor age is older. For group-velocity with periods of less than $36 \mathrm{sec}$, the Parece Vela basin shows a higher group-velocity than the whole West Philippine plate, which might indicate a thinner crust and relatively higher velocity in the upper-mantle lid than in the rest of the regions. Murauchi et al. (1968) suggested a high $P_{n}$ velocity of about $8.4 \mathrm{~km} \mathrm{sec}^{-1}$ beneath the Parece Vela basin, larger than that of the Western Philippine Sea Basin, which has a $P_{n}$ velocity of about $8.0 \mathrm{~km} \mathrm{sec}^{-1}$. Our results seem to agree with these facts. In addition, at the 20 -sec period, a few relatively lower group velocities appear in some regions of the West Philippine and Shikoku basins, which might be a result of a thicker water-layer and crust. At periods of $80-120$ $\mathrm{sec}$, both the group- and phase-velocity maps become smooth, which implies the existence of a nearly homogeneous mantle in this region at depths of $100-200 \mathrm{~km}$. A specific feature of the maps is that the group velocities remain almost constant from 36 to $120 \mathrm{sec}$ in the region of the Eastern Volcano Belt and Active Marginal Basin. We deduce that there is no obvious velocity change between lithosphere and asthenosphere to about a depth of $100 \mathrm{~km}$ in this region. This seems to be somewhat different from previous studies (e.g., Seekins and Teng 1977; Yu and Chang 1991; Oda and Senna 1994). From phase-velocity with periods greater than $50 \mathrm{sec}$, high velocity entering the Eastern Volcano Belt and Active Marginal Basin should be related to the subduction of the Pacific plate.

One remarkable feature appears in the West Philippine Basin, that is, a relatively high group- and phase-velocity distribution on both sides of the Central Basin Ridge, which is an extinct spreading center in the West Philippine Basin (Ben-Avraham et al. 1972). In addition, the high velocity migrates toward the north and south from the Central Basin Ridge with 
increasing period. This result closely matches the evolution of the tectonic processes of the Philippine Sea Basin, and seems to verify the existence of the Central Basin Ridge, which has so far been inactive. As already mentioned, the overall features of our high resolution groupand phase-velocity maps of the Philippine Sea Basin are consistent with the tectonic evolution described in previous studies (Hussong and Uyeda 1981; Seno and Maruyama 1984; Seno 1988; Hall et al. 1995; Okino et al. 1994, 1998; Sdrolias et al. 2004).

To verify the better resolution of the 2-D regional velocity maps described in this study, we compare an example of the 40-sec group- and phase-velocity results with previous globalscale studies (Ekström et al. 1997; Larson and Ekström 2001); see Fig. 11. From Fig. 11, it can be see that our results provide better patterns of velocity variation, when compared with geological configurations, than the results given by Ekström et al. (1997) and Larson and Ekström (2001) for the Philippine Sea region. This can be also accounted for by the fact that a study on a regional scale is more suitable for the interpretation of regional velocity variations than that on a global scale.



Fig. 11. Comparison of the group- and phase-velocity of this study and those of Larson and Ekström (2001) and Ekström et al. (1997) at the 40-sec period. 


\section{CONCLUSIONS}

In this study, high resolution 2-D group and phase-velocity maps of the Philippine Sea region are constructed via tomographic inversion from more than 2500 Rayleigh-wave dispersion curves at periods from 20 to $120 \mathrm{sec}$. We use an optimal damping value estimated from the approximate cross-validation method (cf. van Heijst and Woodhouse 1999) to yield the tomographic inversion and to find the final group- and phase-velocity maps. The results show that both the group- and phase-velocity variation patterns for these periods match up with the geological structural features quite well and are consistent with previous studies on magnetic anomalies and evolutionary history (Hussong and Uyeda 1981; Seno and Maruyama 1984; Seno 1988; Hall et al. 1995; Okino et al. 1994, 1998; Sdrolias et al. 2004). The period of the highest group-velocity for the western Philippine Sea Basin is about $40 \mathrm{sec}$ and for the eastern one is about $32 \mathrm{sec}$. This indicates that the lithosphere is thinner in the eastern region than in the western one, connected to plate cooling.

In particular, there is almost symmetrical high group- and phase-velocity on both sides of the Central Basin Ridge. These high velocities migrate away from the ridge with increasing period. This is in good agreement with the evolutionary history of the Philippine Sea Basin and can be interpreted as supporting the existence of the Central Basin Ridge, which is inactive at present (Ben-Avraham et al. 1972). The group- and phase-velocity distributions at periods longer than $80 \mathrm{sec}$ become smooth throughout the whole Philippine Sea Basin, which implies that the upper mantle beneath this region is nearly homogeneous at depths of $100-200 \mathrm{~km}$. Moreover, the group velocities in the region of the East Volcano Belt and Active Marginal Basin remain almost constant in the $36-120 \mathrm{sec}$ period range, which may indicate that the change in velocity between the lithosphere and the asthenosphere is probably not obvious in this area. These maps of group- and phase-velocity of surface waves are not the real $S$-wave velocity distribution under the Philippine Sea region. Hence, we only give qualitative interpretations in the study area. Only through velocity structure inversion, can the $S$-wave velocity structure be exactly revealed. However, our high resolution maps coincide well with the geological and topographic features and evolutionary history of the study region. For a better understanding of velocity variations under the Philippine Sea Basin, a detailed 3-D $S$-wave velocity structure of the lithosphere in the Philippine Sea region will be described in a future paper.

Acknowledgements The waveform and metadata required in this study are obtained from the facilities of the IRIS Data Management System of the IRIS Data Management Center. The IRIS DMS is funded through the National Science Foundation that is the GEO Directorate through the Instrumentation and Facilities Program of the National Science Foundation under Cooperative Agreement EAR-0004370. We would like to expressly thank the OPH DMC (Ocean Hemisphere Project Data Management Center) for providing the high-quality broadband seismic data. We would also like to especially thank the two anonymous reviewers for their suggestions which have aided in the improvement of this manuscript. This study is financially supported by grants from the National Science Council, ROC, under Nos. NSC92-2116M-238-001 and NSC93-2119-M-238-001. 


\section{REFERENCES}

Ben-Avraham, Z., C. Bowin, and J. Segawa, 1972: An extinct spreading centre in the Philippine Sea. Nature, 240, 453-455.

Dziewonski, A., S. Bloch, and M. Landisman, 1969: A technique for the analysis of transient seismic signals. Bull. Seismol. Soc. Am., 59, 427-444.

Ekström, G., J. Tromp, and E. W. F. Larson, 1997: Measurements and global models of surface wave propagation. J. Geophys. Res., 102, 8137-8157.

Hall, R., J. R. Ali, C. D. Anderson, and S. J. Baker, 1995: Origin and motion history of the Philippine Sea Plate. Tectonophysics, 251, 229-250.

Herrmann, R. B., 1973: Some aspects of band-pass filtering of surface waves. Bull. Seismol. Soc. Am., 63, 663-671.

Hussong, D. M., and S. Uyeda, 1981: Tectonic processes and the history of the Mariana Arc, A synthesis of the results of Deep Sea Drilling leg 60. In: Hussong, D. M., and S. Uyeda (Eds.), Initial Reports of the Deep Sea Drilling Project, US Government Printing Office Washington, DC, 60, 909-929.

Hwang, R. D., 1999: Upper Mantle structure of the mainland China from surface wave dispersion data. Ph.D. Thesis, National Central University, Chung-Li, Taiwan, ROC, 135 pp.

Isse, T., H. Shiobara, Y. Fukao, K. Mochizuki, T. Kanazawa, H. Sugioka, S. Kodaira, R. Hino, and D. Suetsugu, 2004: Rayleigh wave phase velocity measurements across the Philippine sea from a broad-band OBS array. Geophys. J. Int., 158, 257-266.

Knopoff, L., 1969: Phase and group slownesses in inhomogeneous media. J. Geophys. Res., 74, 1701.

Larson, E. W. F., and G. Ekström, 2001: Global models of surface wave group velocity. Pure Appl. Geophys., 158, 1377-1400.

Lebedev, S., G.. Nolet, and R. D. van der Hilst, 1997: The upper mantle beneath the Philippine Sea region from waveform inversions. Geophys. Res. Lett., 24, 1851-1854.

Levshin, A. L., M. Barmin, M. H. Ritzwoller, and J. Trampert, 2005: Minor-arc and major-arc global surface wave diffraction tomography. Phys. Earth Planet. Inter., 149, 205-223.

Menke, W., 1989: Geophysical Data Analysis: Discrete Inversion Theory. Academic Press, London, $289 \mathrm{pp}$.

Murauchi, S., N. Den, S. Asano, H. Hotta, T. Yoshii, T. Asanuma, K. Hagiwara, K. Ichikawa, T. Sato, W. J. Ludwig, W. J. Ewing, N. T. Edgar, and R. E. Houtz, 1968: Crustal structure of the Philippine Sea. J. Geophys. Res., 73, 3143-3171.

Nakamura, Y., and T. Shibutani, 1998: Three-dimensional shear wave velocity structure in the upper mantle beneath the Philippine Sea region. Earth Planets Space, 50, 939-992.

Oda, H., and N. Senna, 1994: Regional variation in surface wave group velocities in the Philipine Sea. Tectonophysics, 233, 265-277.

Okino, K., Y. Shimakawa, and S. Nagaoka, 1994: Evolution of the Shikoku Basin. J. Geomag. Geoelectr., 46, 463-479.

Okino, K., S. Kasuga, and Y. Ohara, 1998: A new scenario of the Parece Vela Basin genesis. Mar. Geophys. Res., 20, 21-40. 
Press, W. H., B. P. Flannery, S. A. Teakolsky, and W. T. Vetterling, 1992: Numerical Recipes. Cambridge University Press, New York, 963 pp.

Sdrolias, M., W. R. Roest, and R. D. Müller, 2004: An expression of Philippine Sea plate rotation: The PareceVela and Shikoku basin. Tectonophysics, 394, 69-86.

Seekins, L. C., and T. L. Teng, 1977: Lateral variations in the structure of the Philippine Sea Plate. J. Geophys. Res., 82, 317-324.

Seno, T., 1988: Tectonic evolution of the West Philippine basin. Mod. Geol., 12, 481-495.

Seno, T., and S. Maruyama, 1984: Paleogeographic reconstruction and origin of the Philippine Sea. Tectonophysics, 102, 53-84.

Sieminski, A., J. J. Lévêque, and R. Debayle, 2004: Can finite-frequency effects be accounted for in ray theory surface wave tomography? Geophys. Res. Lett., 31, L24614, doi:10. 1029/2004GL021402.

Suetsugu, D., and I. Nakanishi, 1987: Regional and azimuthal dependence of phase velocities of mantle Rayleigh waves in the Pacific ocean. Phys. Earth Planet Inter., 47, 230-245.

Trampert, J., and J. Spetzler, 2006: Surface wave tomography: Finite-frequency effects lost in the null space. Geophys. J. Int., 164, 394-400.

Tsai, M. T., 1993: Upper mantle structure variations of the Philippine sea basin and southeastern China from surface wave data. Master Thesis, Institute of Geophysics, National Central University, Chung-Li, Taiwan, ROC.

van Heijst, H. J., and J. Woodhouse, 1999: Global high-resolution phase velocity distributions of overtone and fundamental-mode surface waves determined by mode branch stripping. Geophys. J. Int., 137, 601-620.

Wang, C. Y., 1981: Wave theory for seismogram synthesis. Ph.D. Thesis, Saint Louis University, Saint Louis, 235 pp.

Watanabe, T., D. Epp, S. Uyeda, M. Langseth, and M. Yasui, 1970: Heat flow in the Philippine Sea. Tectonophysics, 10, 205-224.

Yu, G. K., and B. J. Mitchell, 1979: Regionalized shear velocity models of the Pacific upper mantle from observed Love and Rayleigh wave dispersion. Geophys. J. R. Astr. Soc., $\mathbf{5 7}, 311-341$

Yu, G. K., and W. Y. Chang, 1991: Lateral variations in upper mantle structure of the Philippine Sea basin. Terr. Atmos. Ocean. Sci., 2, 281-296.

Zhou, Y., F. A. Dahlen, G. Nolet, and G. Laske, 2005: Finite-frequency effects in global surfacewave tomography. Geophys. J. Int., 163, 1087-1111.

Chang, W. Y., G. K. Yu, R. D. Hwang, and J. K. Chiu, 2007: Lateral variations of Rayleighwave dispersions in the Philippine Sea region. Terr. Atmos. Ocean. Sci., 18, 859-878, doi: 10.3319/TAO.2007.18.5.859(T). 